\title{
Teaching Generation Y College Students: Three Initiatives
}

Susan P. Eisner, (E-mail: seisner@ ramapo.edu), Ramapo College of New Jersey

\begin{abstract}
This paper presents three initiatives created to teach Generation $Y$ students in an undergraduate general education class. The Performance Contract, Investigative Report, and Class Game Show are described.
\end{abstract}

\section{Introduction}

$7 \mathrm{t}$ is not unusual for even veteran college instructors to express some bewilderment about teaching today's students. Pedagogy that these instructors previously used no longer seems to be as effective. They describe students in terms ranging from restless to disinterested. They speak of having to spend more time on classroom management to motivate students to engage with material, and to create a positive learning environment. Many long-time instructors say that college students seem to have changed, and suggest that pedagogical initiatives may be useful in teaching them (Weimer, 2003; Spence, 2001; Sporer, 2001) ${ }^{\mathrm{i}}$.

At the same time, studies report that young people in the U.S. increasingly expect to pursue a college education. By 2001, 63\% of U.S. teenagers planned to attend college full-time. In addition, $24 \%$ of those not planning to attend college full-time expected to attend part-time (Robison, 2002).

Might it be helpful to identify relevant characteristics of today's Generation Y college students, and design pedagogy to reach them? This paper presents three initiatives created through that process for an undergraduate general education class: the Performance Contract, Investigative Report, and Class Game Show. They appear to be effective teaching tools.

\section{Wired and Worldy}

Generation Y (Gen Y) generally refers to the 72 million Americans born from 1977 to 1994. Their shared generational experiences include 9/11, the Columbine shootings, the impeachment of a President, and the Dot Bust. Most of Gen Y is employed, which contributes to its independent streak. At the same time, Gen Y-ers connect strongly with their parents, whom they admire most. Gen Y tends to bypass mainstream media and advertising, and prefers video games and DVDs to broadcast TV and film (Weiss, 2003).

To say Gen Y is technologically literate is an understatement. Generation Y is used to "connexity;" many are most at home in a virtual world. Each week, 18-24 year olds average 10 hours online, 10 hours watching TV, and five hours listening to radio. They are the most interactive generation. A majority of Gen Y engages in video games and instant messaging, and more than one-third downloads music. Gen Y-ers may be best reached by wordof-mouth messages, which spreads quickly through the technology they frequent (Weiss, 2003).

On the whole, Gen Y is averse to taking risks, distrusts mass media, and responds to loud and quick visuals, audio, and music. It favors programs and messages that reflect its lifestyles and core values, and that have humor and emotion. Gen Y values include diversity and equality, in professional and personal arena. Gen Y-ers enjoy spending time with friends, as well as with media and entertainment. They don't like hard sell, and are reached 
more by "fun" than by specifications; they will get the facts on their own. They have more discretionary income than prior generations, but change brand loyalty quickly. Their immersion in the Internet, Talk Shows, and reality programming make it seem natural for all voices to be heard. As a result, Gen Y has a populist sense that anyone can be a star, and feels that there is no one right answer. Gen Y-ers tend to naturally challenge what is being said, and have a "prove it to me mentality" (Morton, 2002).

In the workplace, too, Gen $\mathrm{Y}$ is anything but passive, and wants something in return for what it gives. Gen Y-ers seek and value training, a positive company culture, open and positive bosses, empowerment, flexibility, mutual loyalty and respect, and work-life balance. Linda Morton describes employers seeking to train Gen Y employees as expressing frustrations similar to those educators have. Having grown up with ever-changing technology, an average of 62 TV channels, MTV, and video games, Gen Y seems not to respond to training using traditional manuals or lecture methods. As a result, some employers are migrating to video game formats to train their young workers (Morton, 2002). The military is among those who has turned to digital game-based learning as the most effective way to train Gen Y (Salopek, 2003)

The Gen Y employee tends to accept authority, follow the rules, cooperate as a team player, and have a global orientation (Infante, 2001). Moreover, the Gen Y employee tends to be positive, confident, technically able, self-focused, and ready to leave for something better. Davis Bushnell finds it important to keep the work "interesting and new," given the fast-paced and changing environment that Gen Y requires (Bushnell, 2001).

Joanne Sujansky concurs. She describes Gen Y workers as energetic, enthusiastic, and ready for any challenge. They have the skills and experience of those who are older, can multi-task, and work well in groups. They embrace recognition and reward, care about how their work fits in with the big picture, and do not want to be bored. As a result, they respond best to a coaching management style: "The traditional 'I tell/you do' school of management will not cut it." What characterizes the recommended "coaching" approach? On the whole, Gen Y will respond to being developed and trained, asked to contribute their ideas, given opportunities to progress, provided challenging and meaningful work, and praised along with provided corrective feedback (Sujansky, 2002).

Juxtaposed with its bent for the positive, Gen Y appears to feel it is living in an uncertain world. A majority of 18-29 year olds are very worried about future terrorist attacks taking place in the U.S., available and affordable healthcare, and crime and violence. While concerns about possible future terrorist attacks stayed the same or dropped for other age categories in the last year, Generation Y's level of concern rose form $51 \%$ in 2002 to $61 \%$ in 2003 (Lyons, 2003, July 15).

This generation, then, is not only plugged in; it is connected. It is tolerant, demanding, caring, savvy, and somewhat anxious. It is worldly as well as wired. It is immersed in an increasingly "fun-focused" economy, where entertainment and experience factors increasingly drive consumer choice (Wolf, 1998). In their young lives, Gen Yers have already experienced historic highs and lows. Michael Weiss expresses the resulting quandary this way:

"What should we make of a generation peering into adulthood whose sensibilities were shaped by years of calm followed by days like Columbine and September 11, by years of economic exuberance followed by months and months of recession, and by years of world peace followed by weeks and weeks of wars whose end is nowhere in sight (Weiss, 2003)?"

\section{Digital and Switching}

Jennifer Salopek describes Gen Y-ers as "digital natives" whose developing minds have learned to adapt to speed and thrive on it. Having used technology throughout their lives, Gen Y operates both faster and differently than previous generations. Its video games accustom it to "twitch speed," MTV (its favorite cable channel) accustoms it to processing 100 images per minute, and special effects films accustom it to ultra-rapid action. The result? Gen Y'ers are skilled at parallel processing. They are accustomed to randomly accessed information, instead of linear thinking. Graphics are expected. Worldwide communication is the norm, as it constant connection. 
Operating modes are active, and preferred to passive. Work and play intersect. Achievement and winning are important. Experiences without obvious payoffs are frustrating (2003).

Gen Y seems to be confounding most of the arena it enters. Like educators and employers, entertainment and media industries are experiencing the newness of Gen Y's presence. Orwall describes Gen Y-ers as being hard to "reel in," as confounding Hollywood by failing to turn to films that have traditionally attracted their age group. The most media-literate generation, Gen Y tends to be immune to traditional marketing and promotion. Instead, it relies on movie information it receives through word-of-mouth critique spread through peers via the Internet (Orwall, 2000).

Television broadcasters are also being confronted with Gen Y's non-traditional choices, especially as seen in young males. Nielsen attributes young men's drop in TV viewing to their increased use of video games and DVDs. Video game usage among men ages 18-24 increased 9\% this year (Tribune, 2003). Video games are a part of most teens' lives. Some $74 \%$ say they play at least one hour per week; $34 \%$ say they play $6+$ hours per week (Crabtree, 2003).

What programming attracts Gen Y-ers? "Reality" appears to be their genre. Betsy Frank sees Gen Y-er attraction to such programming as stemming from its being "current, urgent, and of-the-moment ... (it) validates and connects with viewers ... (it is) directly relevant to them at this stage in their lives ... This is an audience to whom relevance is everything." Reality programming seems to mirror the way Gen Y accesses and processes information and entertainment; it engages them by connecting with the lives they lead (Frank, 2003).

Donna Freydkin describes the attraction of reality programming for young viewers as, "The lure of the hunt, the competition ... the reflection of their lives." Gen Y-ers watch less TV than older viewers, and quickly change the channel or turn to cable "if they don't instantly love, or aren't intrigued by, what they see." They enjoy seeing people like themselves put into situations where the stakes are high (Freydkin, 2003).

The reality genre appears to reach Gen Y regardless of media. Young viewers prefer films that reflect those they know in real life (Orwall, 2000). They watch reality shows in far larger number than they have watched anything else on TV (Carter, 2003). Additionally, video games allow them to create their own reality, and the Internet allows instant customization. Frank explains it this way: "In their world, they need only be exposed to things immediately relevant to them and nothing more. Their mantra might as well be "what I want when I want it"'(Frank, 2003).

There appears to be a consistency to Gen $\mathrm{Y}$ whatever sphere they enter. They appear to be wired and worldly, digital and switching. The following initiatives were designed, as a result, as learning tools to better reach Gen Y freshman in the required business, government, and society course.

\section{Initiative 1: The Performance Contract}

Reviewing results of mid-term exams revealed an interesting pattern. Performance on exams in each of several recent semesters has averaged five points less than in previous years. Overall, current students performed their best on the objective sections of their exams. These sections contained both multiple choice and true/false questions of above average difficulty spanning many chapters. Current students performed less well on subjective sections. These sections contained a comprehensive essay to be written in class, and an analytic memo report to be written out of class. Performance on both of the subjective writing sections was similar, suggesting that neither the amount of time available nor the setting was a key factor.

It is not unusual to observe disappointing writing skills among students. Educators of all grade levels are confronting basic errors in composition and grammar. The additional tendency observed here, though, was the simplicity of expression that substituted generalization and unsupported opinion for application of specific course learning. 
Comparing performance on objective sections with results of subjective sections was revealing. Results on objective sections showed that students were capable of grasping and retaining a quantity of material. They appeared to be most proficient at anticipating and memorizing answers to specific questions. Results on subjective sections, on the other hand, suggested that students were not conducting deep learning. Material was not being processed in ways resulting in extrapolation and application.

As an instructor, the ensuing challenge was what feedback to provide students with when returning the exams. Focusing on the positive results of the objective sections might be well received by students, but would be incomplete and misleading. Alternatively, chiding students for not learning deeply enough to perform well on the subjective sections might only trigger a defensiveness that would reinforce their current patterns. Moreover, lecturing on the importance of critical thinking and communication, and presenting the requisite study skills, was an integral feature of the course and had already been done. It seemed the time to do something else.

On the day the exams were to be returned, I piled the exams on the instructor desk that is in full view of the students. But I made no reference to returning the exams, or to how well the class had performed. Instead, students were polled on the open and closed-ended questions that appear in Figure 1. Answers to closed-ended questions were anonymous, to eliminate peer pressure from affecting the answers.

Figure 1: Questions And Representative Student Answers.

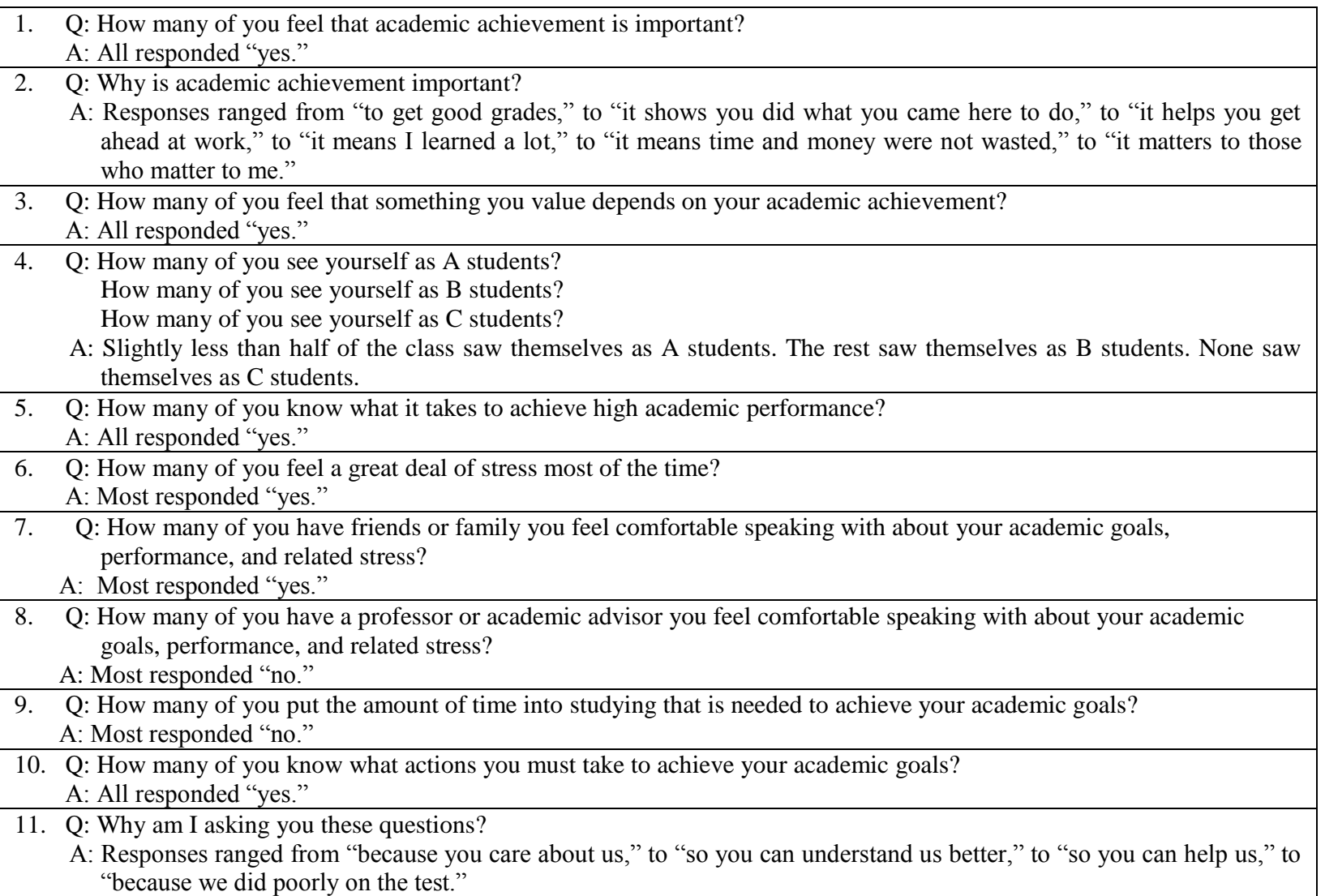

Next, each student was told to think about three things: 1) what s/he is most proud of having achieved during the academic year so far, 2) what s/he would most like to achieve in the remaining weeks of the semester, and 3) what action s/he can take to achieve that goal. Students were asked to report, informally from their seats, their 
answers to those three questions. They looked at each other attentively throughout, listened actively, and nodded empathetically. Proscriptions were frank, appropriate, and sophisticated. Everything that an instructor might have said to them was said - and more. But the students were speaking to and with each other. Peer contact and learning were occurring.

Subsequently, students were asked if they had any questions about how to improve their study or testtaking skills. Their questions ranged from how to manage time, to how to avoid distractions, to how to retain material. Where other students could make suggestions, they did so. Where they could not, I provided the requested techniques.

Following that discussion, students were told they were being given an opportunity, and that each student had the choice to accept or reject that opportunity for him/herself. Those who chose to could formulate a "Performance Contract." That entailed writing a thoughtful and specific typed memo identifying individual performance goals in the class for the balance of the semester, and detailing actions to be taken by the student to achieve those goals. The goals and actions would come from each student, not from the instructor. Students whose Performance Contracts were complete would have their final exam grade compared to their midterm exam grade. Those whose strategies had resulted in an improvement of five or more points would have their overall course grade improved by one point. Performance Contracts would be accepted only at the next class meeting.

Virtually every student chose to submit a Performance Contract. All submitted reflective, precise, and strategic action plans. The writing was significantly stronger than it had been on the subjective sections of the midterm exam. Figure 2 contains representative excerpts from Performance Contracts written by students.

Figure 2: Representative Student Excerpts

- I will try and get more sleep. While reading something in the book that I don't understand, I will make a note of it and ask the professor before, after, or during a class discussion for further clarification. I will stay on top of my work and will not let myself get behind so I don't have to stress at the last minute. I don't like stress! I would like to get better grades. In order for me to do that I must study more.

- I realize that my performance has not been up to par lately and I have decided to change that. In order to do so I realize that I will need to make many changes in my study habits. One thing that I feel I could do to improve my performance would be to prepare myself prior to class by reading the chapters before they are taught. Usually I will take notes in class and briefly skim the chapter afterwards. I understand that this is the wrong way to study and learn, so I have decided to change that.

- What am I going to do to ensure myself a higher grade in this class? I will focus my time management better. This includes setting more time aside for studying, creating questions about the reading and reviewing notes right after class to see if I can answer the questions, making study guides and spending enough time reflecting on them, and getting more sleep instead of staying out until 3 A.M. when I have an 8:30 morning class.

- $\quad$ Although I am doing well in this class, there is still some room for improvement in my work habits. I will review the assigned material before and after we go over it in class to ensure perfect comprehension. I will use a detailed schedule to manage my time more efficiently. I will study with other students every week, as well as just before the exam.

- $\quad$ From now on I plan to work harder. During the first part of this semester I allowed family problems to get in the way. Looking ahead, I am going to focus on my studies instead. I only have one opportunity to get the most I can out of this class and that time is now. I have set high standards for myself to follow, and I need to stop disappointing my professor and myself.

- $\quad$ There are many steps that I need to take in order to improve my performance in this class, but the main thing for me to improve upon would be my study habits. When I have to study for a test I should go someplace that is quiet where I can concentrate. This way I can focus on my work and not on everything that is going on around me. I should go to the library where I can sit down and concentrate on my work. I could also be a lot more organized. I have a tendency to just fold papers up and put them in my books, and sometimes they fall out and sometimes I misplace them. I would not lose papers that often if I used a folder to be more organized. This would help me keep track of important papers that help me to study. Finally, if I took better notes in class I would listen better, learn more, and improve my grades.

In the weeks and months following submission of student Performance Contracts, the level and amount of dialog when discussing course material were heightened. It became clear that most students were now preparing for 
every class, where they had previously reserved studying for the night before an exam. It was also evident that students were now wrestling with comprehension, where they had previously been straining to memorize. The potential of one point being added to one's final grade was hardly significant enough to be the catalyst. It took close to an hour of class time to achieve. But the Performance Contract, and the process by which it was presented, appear to be reaching Generation Y and contributing to student earning.

\section{Initiative 2: The Investigative Report}

Studies correlate low levels of international understanding with low levels of following international developments. Most Americans track international news only when major developments occur, though they keep up with national and local news regularly. At the same time, interest in international news tends to increase as education increases (Pew Research Center for the People \& the Press, 2002). In our increasingly global lives, it is a curricular goal of many college programs to further the international awareness and knowledge of our students. Ramapo College of New Jersey, where I teach, includes global and multicultural understanding among its key planks. The events subsequent to 9/11/01 and War with Iraq appear to have heightened student consciousness of countries other than the United States, and student perception about the gaps in student knowledge about those countries. A teachable moment may be present.

As a result, I put the following words on the board in my freshman Perspectives of Business and Society class: Chechnya, China, India, Indonesia, Iran, Iraq, Lebanon, Liberia, Israel, Pakistan, Philippines, Saudi Arabia, Somalia, and Yemen. In the business, government, and society course, international and interdisciplinary perspectives are central. It is part of the General Education core, a four-credit course, and enrolled by up to thirtyfive students per section. In a typical section, five students are international students.

All of the countries listed on the board were topics of stories receiving recurring media attention. Students were asked which of the countries they had direct knowledge of either through prior research or life experience. China, India, Israel, and Pakistan were identified. Students were asked to share their knowledge of those countries with the class on two tracks: 1) how do business, government, and society function in the country each was familiar with; and 2) how does the relationship of those institutions within that country compare with the relationship of those institutions within the United States? No student could answer those two questions. I asked the class to locate the fourteen countries in the original list on a map. As a whole, they were unable to do so. Few students could locate more than three or four of the countries. It appeared that a basic level of understanding needed to be learned before more complex interrelationships could be analyzed.

Each student was asked to select the five countries from those listed on the board that s/he was most interested in learning more about. From those lists, students with common interests were put into groups averaging four students each. Together, they prioritized nine countries. Each group was told what country they had commonly highlighted.

The groups were told they would be conducting collective research about the countries. Little enthusiasm was shown. They were then informed that they would be simulating Investigative Reporters, and that the country they had selected would be their "beat." Reports would be delivered in a roundtable setting similar to those used in television news programs. Each group would report in a ten minute "segment." A positive response was immediate. The learning goal had not changed. But repositioning the means appeared to produce interest in achieving it.

The groups were instructed to begin covering their beat. They were told to see the country they were covering through the eyes of those who knew little about it, and to report facts foundational to understanding. Baffled looks indicated that this was still too intricate a place to start. So the groups were given sample questions to consider in preparing their reports, which were to be presented about one week later when the class next met. Each group was told to report on both the country it had collectively prioritized, and the United States. Figure 3 contains the questions given to the groups. 
Figure 3: Questions Given To Student Groups Simulating Investigative Reporters.

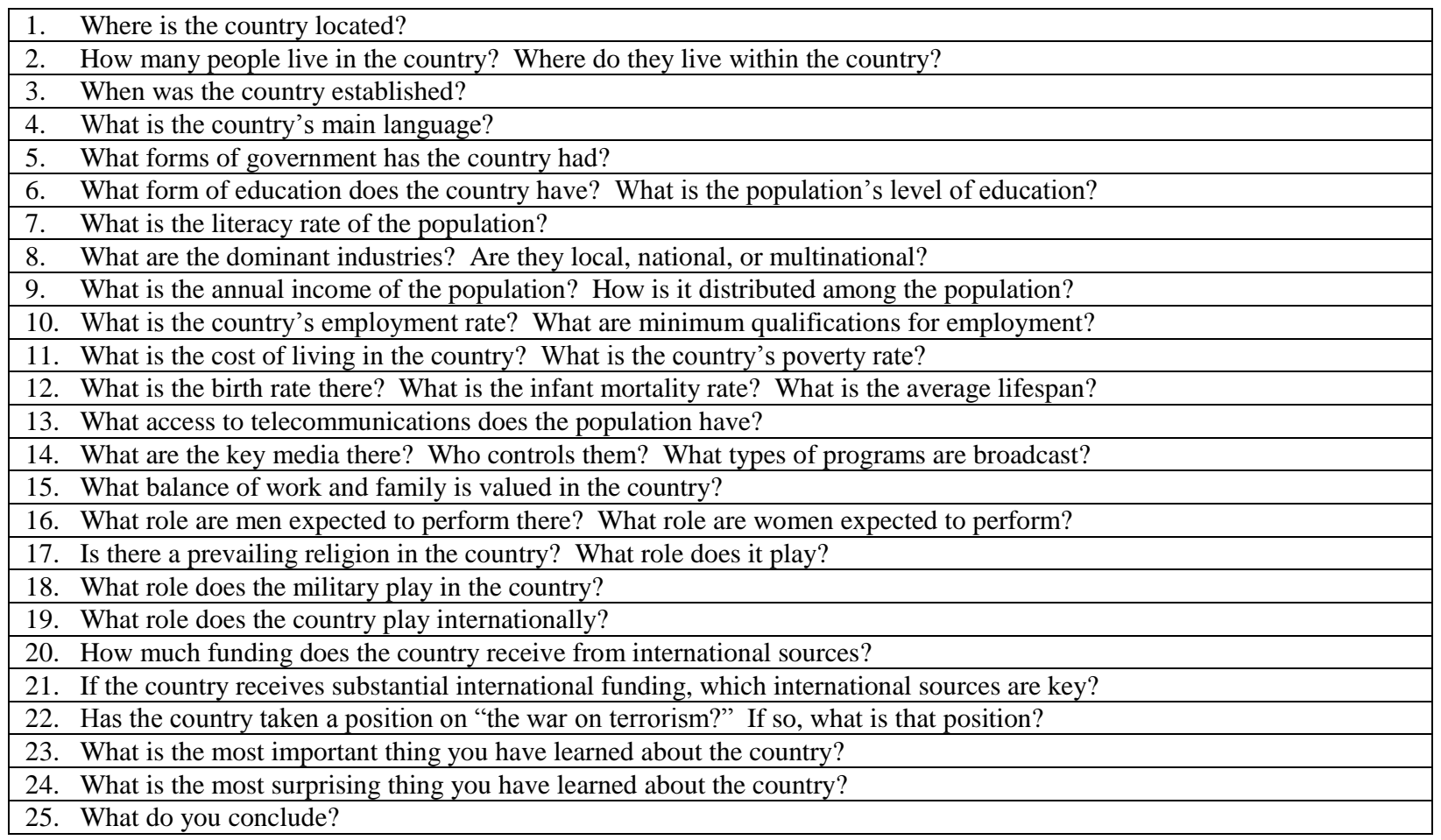

The list of questions was long, especially to those of us who learned how to conduct research in preInternet times. I was concerned that the students had been asked to do too much, too quickly; they had been told that reports were to be presented at the next class. What if they chose to do nothing, rather than find out what they could do?

The next class was planned to set aside the first half of the session for groups to meet, synthesize their findings, and prepare to report. It was not necessary. The groups had taken the initiative to meet between classes, divide the labor, regroup, and prepare their reports. All but one of the nine groups arrived not only ready to report, but anticipating competitive performance and wanting to be the group that delivered the best Investigative Report.

On the whole, the recommended questions were answered. Even more important were the attentiveness and participation of students during the reports, the vitality and currency of the presentations, and the level of inquiry stimulated and addressed. Initiative beyond that expected was evidenced in additional areas explored by most groups, keen insights found, and sound conclusions reported. They requested that they be allowed longer segments in which to report.

The class was de-briefed immediately following the reports. Students repeatedly commented that they have taken their own country and way of life for granted. Significantly, every group noted that student knowledge of countries outside the United States is insufficient, and that student knowledge of the United States should also be further pursued.

It should have been of little surprise, then, when students in subsequent sessions of my Organizational Behavior class came to similar conclusions. This is a 300-level course required of all Business majors. One of the simulations we perform is of a family considering whether or not to accept an expatriate assignment offered to one of the adults in the family by his/her employer. Each group is given a specific country to consider for this relocation. Countries have included Afghanistan, Argentina, Australia, Brazil, Canada, Egypt, France, Germany, 
Ghana, Italy, Hong Kong, Japan, Mexico, Peru, Russia, Spain, the United Kingdom, and Zambia. In most cases, the group rejects the assignment. Groups who accept the assignment tend to have been offered Australia, Canada, or the United Kingdom; they cite similarity of language to their own as the reason. In the ensuing discussion, students tend to eventually report concern about their own ethnocentricity. They are then told of the Investigative Report experience of the Perspectives of Business and Society class, as a basis for commonality when identifying the international arena as a focus for future learning. Many students in the Organizational Behavior class subsequently enroll in one of the Study Abroad or International Coop programs offered by the college. They report their "need to know" first-hand about other countries to have been stimulated by this simulation. In their own way, and of their own initiative, they too appear to be ready to simulate Investigative Reporters.

\section{Initiative 3: The Class Game Show}

When it comes to testing, some instructors prefer to give frequent quizzes focusing on a module of material close to when it is presented. They feel this helps students develop solid study habits, increases student preparedness for class, and maintains student focus on the course. Other instructors prefer to give long-form midterm and end-term exams synthesizing material that has been covered during several weeks and months. They feel this provides students with a perspective they might not otherwise have gained, increases their long-term retention of course material, and helps students become responsible for their own learning and time management ${ }^{\mathrm{ii}}$. I fall into the latter category. My students tend to be assessed comprehensively at five-week intervals. But I also recognize the value of intermittent assessment, and of reviewing material after it is covered. The Game Show was created, as a result.

The first of three long-form exams in my Perspectives of Business and Society course is a 90-minute test that covers the first of two textbooks covered during the semester. The book is The Making of Economic Society (Heilbroner and Milberg, 2001). A classic and vivid compilation of world history and public policy told through macroeconomic eyes, the text tends to be either intimidating or exhilarating to the students. Most of the students in this course are freshman. The book was selected for the foundation, perspective, and challenge it provides. It is not a text that can be mastered in one reading the night before an exam.

In recent years, students have seemed to incline toward branding the textbook as too difficult, and to hope that lectures and handouts will substitute for having read it. Prior experience has shown that once students commit to tackling the book, most of them not only come to appreciate it but also to extol it upon completion. The challenge, it appeared, was to stimulate student interest in reading the book.

Several weeks before the first exam, I asked the students if they would like the opportunity to participate in a Class Game Show. They were told the choice would be theirs. The Class Game Show was described to them as detailed in Figure 4. Student response to this opportunity was unanimous and affirmative. The Class Game Show was to be.

The session for the first Class Game Show was planned to allow extra time for teams to compare and select their questions. That turned out to be unnecessary. Most teams had arranged to meet outside of class, and had their questions ready upon arrival. Having allotted extra time was fortuitous, though, as unanticipated needs arose. Students were not adept at writing questions. Several questions turned out to need interpretation and re-write, and many inadvertently asked more than one question at once. Moreover, two students did not attend. Their teams needed extra time to write the missing questions. In addition, the reporting round stimulated unpredicted and avid discussion of course material. 
Figure 4: Elements of the Class Game Show.

1. The class is divided into seven teams of five students each. The seven teams will compete in a Class Game Show.

2. The Class Game Show focuses on seven key chapters from among those the next full-period exam will cover.

3. In the session prior to the Class Game Show, each team is assigned one textbook chapter to write ten true or false questions about before the class next meets. Each student in the team prepares three questions, and brings two versions to class. One version has the answers.

4. In that same session prior to the Class Game Show, each team is assigned a second textbook chapter to answer ten true or false questions about during the Class Game Show. Those questions will come from the class team assigned to write questions based on that chapter.

5. The Class Game Show is held at the next class session. At the start of that session, each team has ten minutes to select ten questions they want the answering team to answer. They select questions from those their team prepared for class; each of the five teammates brings three questions.

6. The instructor collects the ten questions selected by each team, without their answers. Each set of questions is given to the team assigned to answer those questions. Every team serves as both a writing team and an answering team.

7. Each team has ten minutes to collectively answer the ten questions it has been given.

8. At the end of the ten-minute answer period, each team has the opportunity to use the first of two "lifelines." The first lifeline is "ask the class." Using this lifeline, each team polls the class for an answer to any one of the questions it has received.

9. Each team can then use a second lifeline. This lifeline is "look it up." Using this lifeline, each team has three minutes to search the chapter for the answer to any one of its ten questions

10. The reporting round now begins. Teams are called sequentially, according to the chapter whose questions they answered. The entire class observes. Each team reports its answers for each question it was given. The team that wrote the questions reports whether the answering team has answered each question correctly or incorrectly, and reports the correct answer to each question.

11. The instructor moderates throughout to clarify any confusion about questions, intervene if answers are disputed, ensure fairness, and see that answers are scored correctly.

12. All students participate in question writing and answering. All students listen to all questions being answered and scored.

13. The members of the team or teams that receive the most number of correct answers receive extra credit toward their overall course grade.

In that first Class Game Show, two of the teams got all of their answers correct. The experience as a whole seemed a bit unwieldy to me. It was not clear to me if all students had completed the requisite preparation. I was not sure the Class Game Show should be repeated. So students were anonymously polled as to whether they had found this initiative helpful to their learning. Every student responded "yes." They were then asked whether they would like to do another Class Game Show in preparation for their second full-period exam. Again, they all responded "yes." So that I could understand this better, each student was then asked to report what s/he had gained from participation in the Class Game Show. Their responses ranged from "had to read the textbook, which turned out to be interesting," to "got to understand the material better by discussing it with classmates," to "learned it is hard to write test questions," to "reviewed a lot of material listening to and thinking about all the answers given by the teams."

A few weeks before the second full-period exam was to be given, students asked when the next Class Game Show would be. They had not forgotten. The second Class Game Show was scheduled and held. All students attended the second Class Game Show. Questions were far less problematic. Intensity of interest and level of preparation was reflected in the strong quality of discussions between teams as they collaborated to answer their questions. Some answering teams had processed their assigned chapter so well that they rightfully contested the wording of some questions they were given. Students listened attentively to classmate's answers, and took notes during the reporting round. Every team qualified for extra credit. During the debriefing that again followed the Class Game Show, students again reported benefit to learning. They requested that another Class Game Show be held in preparation for their two-hour final exam.

That third Class Game Show was held near the end of the course. Performance was at an even higher level than in the previous Class Game Show. All questions were prepared in advance, all questions were clear, questions tested more advanced understanding, and teams were able to answer questions were quickly. One team found itself 
two members short; a snowstorm had begun, and commuting students faced treacherous driving conditions. That only two students did not attend under those conditions is a positive indicator. Impressively, two other teams offered to give up one of their two lifelines to the team that found itself two members short. What had been thirtythree individuals sharing a timeslot, syllabus, and classroom only weeks earlier appeared to have been transformed. They were now a team of collaborative learners interested in each other's perspectives, supported by one another, connected to the material, and proud of their individual and collective performance.

A colleague who has been a teacher heard about The Class Game Show and asked to observe that third one. Her comments were especially descriptive, as she was seeing it for the first time. She could find no negatives to report. She particularly noted the intensity of student interest, the level of student participation, and the degree of student mastery of material. She expressed it this way: "Student listening was $1000 \%$; you could almost hear them listening to each other. The students were really there. They really got it. And they were clearly enjoying their learning" (Dobelle, 2003).

The student debriefing that followed the third Class Game Show confirmed her positive observations. Figure 5 contains representative student comments regarding the Class Game Show.

Figure 5: Representative Student Comments During The Third Class Game Show De-Briefing.

\begin{tabular}{|ll|}
\hline$\bullet$ & It gave me confidence in what I know, which makes studying for the test less scary and more interesting. \\
\hline$\bullet$ & $\begin{array}{l}\text { Trying to write questions that would trick the other team made me attend more to details in the chapter. Before, I would } \\
\text { just skim when reading. }\end{array}$ \\
\hline$\bullet$ & It was competitive, and I wanted to win. I wanted to be seen as knowing at least as much as everyone else. \\
\hline$\bullet$ & $\begin{array}{l}\text { Knowing that the questions might not be as clear as the questions on the exams made you prepare for the worst and learn } \\
\text { all the more thoroughly. }\end{array}$ \\
\hline- & $\begin{array}{l}\text { Many teams wrote questions I did not anticipate. That teaches me to prepare for anything when studying, and to learn as } \\
\text { much as I can. }\end{array}$ \\
\hline$\bullet$ & $\begin{array}{l}\text { Reading is always hard for me. This made reading the textbook possible. The learning became fun, instead of a chore. It } \\
\text { turned out to be so interesting. }\end{array}$ \\
\hline & It gave me confidence in speaking to the whole class. \\
\hline & $\begin{array}{l}\text { This is something different from what is routinely done in classes. It has made me look forward to and prepare for this } \\
\text { class. It has helped me a lot. It's a cool way to learn. }\end{array}$
\end{tabular}
learning.

The Class Game Show is now a course staple. It appears to be reaching Generation Y, and furthering

\section{Student End-Term Feedback}

At the end of the semester in which the three initiatives described above were introduced, students were surveyed regarding outcomes. Students responded anonymously to questions about the overall effectiveness of each initiative, and about the extent to which specific objectives of each initiative were achieved. Thirty-three of the thirty-five students who completed the course were present and completed the questionnaire. They were mostly male (21 male, and 12 female), of traditional age (31 aged 18-21, and 2 over the age of 26), campus residents (27 live on campus, and 6 live off campus), and freshman ( 30 freshman, 1 sophomore, and 2 seniors). Responses for each question were provided using a scale of 1 (low) to 5 (high).

As detailed in Table 1, students reported that all three initiatives contributed a great deal to their overall learning in the course. Some $94 \%$ found the Class Game Show to be highly effective, $85 \%$ found the Investigative Report to be highly effective, and $66 \%$ found the Performance Contract to be highly effective. 
Table 1: Student Responses Regarding the Extent to Which

The Initiatives Contributed To Their Overall Course Learning.

\begin{tabular}{|lc|c|c|c|}
\hline & Mean (1 low -5 high) & \% 1 or 2 & \% 3 & \% 4 or 5 \\
\hline Class Game Show & 4.4 & 3.0 & 3.0 & 93.9 \\
\hline Investigative Report & 4.0 & 0.0 & 15.2 & 84.8 \\
\hline Performance Contract & 3.6 & 15.6 & 18.8 & 65.6 \\
\hline
\end{tabular}

As seen in Table 2, students reported that every objective of the Class Game Show was strongly achieved. Virtually all of the students $(97 \%)$ said that the Class Game Show greatly increased their understanding of course material. Additionally, some $91 \%$ said it greatly helped them review for exams, $82 \%$ said it greatly increased their connection to other students and the class, $79 \%$ said it raised their academic performance a great deal, $70 \%$ said it strengthened their reading a great deal, and $64 \%$ said it built their confidence in speaking up in class a great deal.

Table 2: Student Responses Regarding The Extent To Which Objectives Of The Class Game Show Were Achieved.

\begin{tabular}{|c|c|c|c|c|}
\hline & Mean (1 low - 5 high) & $\% 1$ or 2 & $\% 3$ & $\% 4$ or 5 \\
\hline Helped me to review for exams & 4.6 & 3.0 & 6.1 & 90.9 \\
\hline Increased my understanding of course material & 4.5 & 3.0 & 0.0 & 97.0 \\
\hline Connected me more to other students and this class & 4.3 & 9.1 & 9.1 & 81.8 \\
\hline Raised my academic performance & 4.0 & 12.1 & 9.1 & 78.8 \\
\hline Strengthened my reading & 3.8 & 18.2 & 12.1 & 69.7 \\
\hline Built my confidence in speaking up in class & 3.8 & 15.2 & 21.2 & 63.6 \\
\hline
\end{tabular}

Objectives of the Investigative Report also appeared to have been achieved. As seen in Table 3, at most $15 \%$ of students reported having experienced any of the objectives to a low extent (\%1 or 2). Nearly $82 \%$ said that the Investigative Report greatly increased their connection to other students and the class, $79 \%$ said it greatly assisted their reporting and presentation skills, $76 \%$ said it greatly aided their development of research skills, $73 \%$ said it greatly increased their knowledge of countries outside the U.S., and $61 \%$ said that it greatly increased their interest in countries outside the U.S. The only desired result that a solid majority did not report to have highly experienced was "raised my desire to follow international developments." But 49\% did report to have highly experienced that, only $15 \%$ reported only a slight increase for that factor, and its mean was a solid 3.4. Responses suggest, then, that this objective was achieved. Interpreting outcomes for this objective is further complicated in that it is unknown if students started the course with a strong desire to follow international developments. If they did, it might be less necessary, and less likely, for the Investigative Report to strongly raise desire to follow international developments.

Table 3: Student Responses Regarding the Extent To Which Objectives Of The Investigative Report Were Achieved.

\begin{tabular}{|lc|c|c|c|}
\hline & Mean (1 low - 5 high) & \% 1 or 2 & \% 3 & \% 4 or 5 \\
\hline Connected me more to other students and this class & 4.2 & 3.0 & 15.2 & 81.8 \\
\hline Assisted my reporting and presentation skills & 4.0 & 6.1 & 15.2 & 78.8 \\
\hline Aided my development of research skills & 4.0 & 3.0 & 21.2 & 75.8 \\
\hline Increased my knowledge of countries outside the U.S. & 3.8 & 12.1 & 15.2 & 72.7 \\
\hline Increased my interest in countries outside the U.S. & 3.6 & 12.1 & 27.3 & 60.6 \\
\hline Raised my desire to follow international developments & 3.4 & 15.2 & 36.4 & 48.5 \\
\hline
\end{tabular}

Although students reported that each of the three initiatives strongly contributed to their overall learning in the course, the Performance Contract ranked third of the three. Still, a majority of students reported that each 
objective of the Performance Contract were strongly achieved. As seen in Table 4, nearly $72 \%$ reported that the Performance Contract greatly helped them develop better study habits, and also greatly increased their attention to the course. Some $69 \%$ reported that the Performance Contract greatly strengthened their use of time management, $66 \%$ said it greatly increased their control over their studies and stress level, 59\% said it greatly increased their academic performance, and $53 \%$ said it greatly increased their participation in class.

Table 4: Student Responses Regarding the Extent To Which Objectives Of The Performance Contract Were Achieved.

\begin{tabular}{|c|c|c|c|c|}
\hline & Mean (1 low -5 high) & $\% 1$ or 2 & $\% 3$ & $\% 4$ or 5 \\
\hline Strengthened my use of time management & 4.0 & 9.4 & 21.9 & 68.8 \\
\hline Increased my attention to this course & 3.9 & 9.4 & 18.8 & 71.9 \\
\hline Helped me to develop better study habits & 3.8 & 12.5 & 15.6 & 71.9 \\
\hline Gave me more control over my studies and stress level & 3.8 & 18.8 & 15.6 & 65.6 \\
\hline Raised my academic performance & 3.6 & 15.6 & 25.0 & 59.4 \\
\hline Improved my participation in class & 3.4 & 31.3 & 15.6 & 53.1 \\
\hline
\end{tabular}

The questionnaire invited open-ended comments from the student respondents. Table 5 contains their comments.

Table 5: Representative Student Comments on the End-Term Questionnaire Regarding the Three Initiatives.

- All three things helped my overall learning.

- The initiatives were great. They clarified a lot of stuff as well as adding variety to the course. They helped me learn new things, and made me aware of what I need to focus my studies on.

- The Game Show did help with extra credit, but it depends on people preparing. If I prepare and others do not, I stop caring.

- I enjoyed doing the Game Show. It helped me a lot. It helped me to understand concepts.

- I think the Game Shows helped a lot, and relaxed the class as well. It was fun and competitive.

- Any type of teamwork is beneficial!

- All the opportunities you gave us to speak really helped me, and I'm sure a lot of students, with class speaking.

- This has to be my favorite course this semester.

The comment regarding the need for student preparation was most useful. To the observer, all students have appeared to participate and contribute fully to the Class Game Shows. On the other hand, few observations are fool proof, and the comment by this student underscores the importance of ensuring student preparation. As a result, instructions for future Class Game Shows will include telling students to write their names on the question sheets they bring to class, since questions will be collected and reviewed by the instructor as an aspect of each student's course participation grade. Students will also be informed that individual preparation for and contribution to team performance in Class Game Shows will be anonymously peer-assessed and reflected in the course participation grade, just like other teamwork in the class.

\section{Discussion}

The positive outcomes of these three initiatives created to help teach Gen Y college students were predicted by the descriptors of generational characteristics that were foundational to the initiatives' design. Other instructors also appear to be experiencing positive results when developing pedagogy that incorporates Gen Y's frame of reference. Ruth Sporer, for instance, has transitioned from giving regular quizzes to giving "no-fault" quizzes. In her experience, the more traditional quizzes caused student anxiety, absence, and requests for make-ups. She then created quizzes that could only improve a students' grade through extra credit for correct answers, learning 
diagnostics, discussion opportunity, and peer tutoring in the classroom. She saw a significant change occur. Student attendance increased, preparation time for unit exams decreased, and cooperation and interpersonal working relationships strengthened. An atmosphere conducive to learning was achieved, and carried over to other situations in which students must work together to complete their work (Sporer, 2001).

Maryellen Weimer also reports the value of designing pedagogy to better reach the Gen Y college student. She, too, finds that effective teaching is learning-centered and incorporates the learning styles of students. To accomplish this, she recommends that faculty involve students more, serve as guides and coaches rather than sages, motivate students to accept responsibility for learning, build student knowledge base by covering less and having students cover more, and include evaluation activities that promote learning and develop assessment skills (Weimer, 2003).

The Gallup Organization concurs. Its 2002 report on effective teaching identified three essential characteristics: solid knowledge of subject-matter, refined teaching skills, and natural talent for teaching. Exceptional teachers have strong impact because they help students learn, win students over, and are motivated by teaching. They feel teaching is their calling, find it enjoyable, believe learning can be fun, and feel a responsibility to students. They set high standards for themselves and their students, and expect and communicate successes. They build affirming relationships with students, give respect to students, and expect respect in return. They are continual learners, strive for continual improvement, and try new things when needed. They maximize learning time, and adapt to unexpected events. In sum, "They provide learning activities that create excitement, enthusiasm, and drama for students ... They structure their teaching so students can learn" (Gallup, 2002).

As founding director of the Schreyer Institute for Innovation in Learning at Penn State University, Larry Spence has worked on more than 170 projects to improve learning skills while reducing costs. He describes the frustration of many of today's teachers, including himself when a new teacher, faced with students that do not study, perform, or retain. Now an experienced teacher, he has come to a frank conclusion: "We won't meet the needs for more and better higher education until professors become designers of learning experiences." Why? Because Gen Y will graduate into a world in which knowledge is constantly changing and lifetime learning has become standard. Spending around $\$ 740$ billion annually for U.S. training and education, and an estimated $\$ 2$ trillion globally, businesses increasingly value employees who are able to learn continually, adaptively, actively, and well. Accordingly, today's college students need to learn how to think, decide, create, and learn. They know how to find facts, which have an increasingly short shelf life (Spence, 2001).

A recent study by the Gallup Organization identified the workplace competencies most needed today. A majority of young employees (18-29 years old) reported the following skills to be critical or very important in doing their job successfully: skill in dealing with people (91\%), critical thinking skills (creative thinking, decision-making, problem-solving; $81 \%$ ), reading speed and comprehension (69\%), basic use of computers (66\%), public speaking (60\%), writing ability (56\%), and basic mathematics (57\%) (Lyons, 2003, August 26). Of these, only basic mathematics is not a skill furthered by the initiatives presented in this paper. Quantitative literacy is outside the purview of the course for which the initiatives have been created.

Further describing today's Gen Y students as "the twitch generation," Spence explains their learning style in stark terms:

"Expecting learning to be about doing, to relate to their interests, to be fun, and to pay off immediately, they strongly resist traditional teaching. Instead, they treat traditional classroom assignments like the throwaway instructions you get with a new computer. They read, regurgitate, and toss ... Only the bribe of credentials keeps students at what they see as meaningless tasks that we set. Consequently, they concentrate on getting their diplomas with as little effort and time as possible (Spence, 2001)." 


\section{Conclusion}

Experiences like those reported above indicate that there is interest among some instructors to create pedagogy that will enable them to better help Gen Y college students to learn. It is neither likely nor suggested here, though, that all instructors will or should share that interest. Faculty members differ in the student populations they teach, subject matter they teach, and styles they most comfortably use when teaching. Using teaching methods we find credible and natural is no doubt a factor in our effectiveness in reaching our students.

The three initiatives and the foundations for them described in this paper, then, are presented for those instructors who share a sense of bafflement regarding how best to reach today's college students. Perhaps replication or adaptation of these initiatives, or pedagogical innovation stimulated by the literature upon which they are founded, will assist these instructors in their efforts to better teach Gen Y.

Such initiatives may be of additional interest to faculty concerned with student retention. Successful acculturation to college during the first year is a particular interest of many academics, since the majority of students entering college do not complete their degree program and the first year appears to be a key predictor of retention. Factors that have been correlated with increased likelihood of retention include lower stress level, greater social integration and support, enhanced self-esteem and confidence, and higher academic performance (Boulter, 2002). Feedback presented above from the freshman level class in which the Performance Contract, Investigative Report, and Class Game Show were initiated indicate that the initiatives contribute positively to those factors, as was predicted by the literature upon which they were constructed. Figures 6 and 7 summarize attributes and outcomes of the three initiatives reflective of characteristics positively associated with Gen Y.

Figure 6. Summary of attributes Gen Y relate to positively contained in the initiatives.

\begin{tabular}{|l|c|c|c|}
\hline & Performance Contract & Investigative Report & Class Game Show \\
\hline Challenging & Yes & Yes & Yes \\
\hline Class-life intersecting & Yes & Yes & Yes \\
\hline Coaching & Yes & Yes & Yes \\
\hline Competitive & Yes & Yes & Yes \\
\hline Empowering & Yes & Yes & Yes \\
\hline Exciting experience & Yes & Yes & Yes \\
\hline Fun & Unknown & Yes & Yes \\
\hline Immediate & Yes & Yes & Yes \\
\hline Interactive/active & Yes & Yes & Yes \\
\hline Learning-centered & Yes & Yes & Yes \\
\hline Mutual respect & Yes & Yes & Yes \\
\hline Opportunity to progress & Yes & Yes & Yes \\
\hline Positive & Yes & Yes & Yes \\
\hline Reality-based & Yes & Yes & Yes \\
\hline Recognition/reward/payoff & Yes & Yes & Yes \\
\hline Teamwork & Unknown & Yes & Yes \\
\hline Technology/media-based & Unknown & Yes & Yes \\
\hline Training/development & Yes & & \\
\hline Populist/voice heard/word-of-mouth & Yes & & \\
\hline
\end{tabular}


Figure 7. Summary of positive outcomes for Gen Y furthered by the initiatives.

\begin{tabular}{|l|c|c|c|}
\hline & Performance Contract & Investigative Report & Class Game Show \\
\hline Academic achievement & Yes & Yes & Yes \\
\hline Attention & Yes & Yes & Yes \\
\hline Computer use & Unknown & Yes & Yes \\
\hline Confidence & Yes & Yes & Yes \\
\hline Connection with others & Yes & Yes & Yes \\
\hline Critical thinking & Yes & Yes & Yes \\
\hline Interpersonal competence & Unknown & Yes & Yes \\
\hline Knowledge & Yes & Yes & Yes \\
\hline Oral communication & Yes & Yes & Yes \\
\hline Reading & Yes & Yes & Yes \\
\hline Responsibility & Yes & Yes & Yes \\
\hline Self/peer assessment & Yes & Yes & Yes \\
\hline Social support & Yes & Yes & Yes \\
\hline Stress reduction & Yes & Yes & Yes \\
\hline Teamwork/cooperation & Yes & Yes & Yes \\
\hline Time management & Yes & & \\
\hline Writing & Yes & & \\
\hline
\end{tabular}

\section{References}

1. Boulter, L. T. (2002, June). "Self-concept as a predictor of college freshman academic adjustment". College_Student Journal 36 (2), 234. Retrieved December 5, 2003, from Academic Search Premier database.

2. Bushnell, D. (2001, February 22). "Younger workers rewriting workplace rules". Boston Globe, G.1. Retrieved December 4, 2003, from ProQuest database.

3. Carter, B. (2003, January 25). "Reality shows alter the way TV does business". New York Times, A.1. Retrieved December 5, 2003, from ProQuest database.

4. Crabtree, S. (2003, September 16). "Grand theft of innocence? Teens and video games". The Gallup Organization. Retrieved December 5, 2003, from Gallup Brain database.

5. Dobelle, Gladys. (2003, December 5). Comments following observation of the Class Game Show at Ramapo College of New Jersey.

6. Frank, B. (2003, July 7). "Check out why young viewers like reality programming”. Broadcasting \& Cable 133 (27), 7. Retrieved December 5, 2003, from ProQuest database.

7. Freydkin, D. (2003, January 15). "Young and voyeuristic". USA Today, D.1. Retrieved December, 5, 2003, from ProQuest database.

8. Gordon, G. (2003, January 7). "Voices of highly effective teachers". The Gallup Organization. Retrieved December 7, 2003, from Gallup Brain database.

9. Heilbroner, R. L, \& Milberg, W. (2001). The Making of Economic Society (11 ${ }^{\text {th }}$ ed.). Prentice Hall.

10. Infante, V. D. (2001, March). Millennials: “A new generation in the workforce”. Workforce 80 (3), 28. Retrieved December 4, 2003, from ProQuest database.

11. Lyons, L. (2003, August 26). "Which skills hold the secret to success at work?" The Gallup Organization. Retrieved December 7, 2003, from Gallup Brain database.

12. Lyons, L. (2003, July 15). “Angst aplenty: Top worries of young Americans”. The Gallup Organization. Retrieved December 5, 2003, from Gallup Brain database.

13. Morton, L. P. (2002, Summer). "Targeting Generation Y”. Public Relations Quarterly 47 (2), $46-48$.

14. Orwall, B. (2000, August 10). "Buying Gen Y: It's Hollywood's turn to scream”. Wall Street Journal, B.1. Retrieved December 4, 2003, from ProQuest database.

15. Pew Research Center for the People \& the Press. (2002, June 9). Public's news habits little changed by September 11. Retrieved December 4, 2003, from http://people-press.org/reports.

16. Robison, J. (2002, February 26). "The future is academic". The Gallup Organization. Retrieved December 5, 2003, from Gallup Brain database. 
17. Salopek, J. J. (2003, June). "Going native: Cross the generation gap by learning to speak". $T+D 57$ (4), 17 (3). Retrieved December 5, 2003, from Academic Search Premier database.

18. Spence, L. D. (2001, November-December). "The case against teaching". Change 33 (6), 10 (10). Retrieved December 5, 2003, from EBSCO database.

19. Sporer, R. (2001, Spring). "The no-fault quiz". College Teaching 49 (2), 61.

20. Sujansky, J. (2002, May). "The critical care and feeding of Generation Y (coach, don't manage)". Workforce 81 (15), 15.

21. Tribune Newspapers. (2003, November 26). "Young men tune out". Chicago Tribune, 44.

22. Weimer, M. (2003, September-October). "Focus on learning, transform teaching". Change 35 (5), 48 (7). Retrieved December 4, 2003, from Expanded Academic database.

23. Weiss, M. J. (2003, September 1). "To be about to be". American Demographics 25 (7). Retrieved December 5, 2003, from Expanded Academic database.

24. Wolf, M. J. (1998). The Entertainment Economy: How Mega-Media Forces Are Transforming Our Lives. Times Books.

\section{Endnotes}

${ }^{\mathrm{i}}$ Conversations with faculty at Ramapo College of New Jersey (Mahwah, New Jersey) and Nassau Community College (Garden City, New York), 2001-2003 concur.

ii From conversations with faculty at Ramapo College of New Jersey (Mahwah, New Jersey) and Nassau Community College (Garden City, New York), 2001-2003.

Notes 